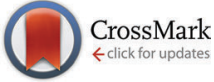

Cite this: J. Mater. Chem. B, 2016, 4, 5683

Received 29th May 2016, Accepted 29th July 2016

DOI: $10.1039 / c 6 t b 01341 d$

www.rsc.org/MaterialsB

\title{
A combined experimental and computational study of the substituent effect on the photodynamic efficacy of amphiphilic Zn(II)phthalocyanines $\dagger$
}

\begin{abstract}
Anzhela Galstyan, ${ }^{\text {ab }}$ Kristina Riehemann, ${ }^{\mathrm{b}}$ Michael Schäfers ${ }^{\mathrm{acd}}$ and Andreas Faust ${ }^{\mathrm{acd}}$
Zinc(I)phthalocyanines (Zn(I)Pc) have shown promising applications in photodynamic therapy due to their high quantum yield of singlet oxygen generation; however, optimization of their overall properties are required before their clinical application as photosensitizers (PSs). The photosensitization efficiency of photoprobes is strongly influenced by the nature of the conjugated moieties and often it can be efficiently tuned by variation in the substitution pattern. Through this study we examined how the structural design of amphiphilic carbohydrate-based Zn(॥)Pcs affects their photophysical properties, binding affinity to human serum albumin (HSA) and photodynamic activity against human cancer melanoma cells. The replacement of oxygen with sulfur at non-peripheral positions of low-symmetry Zn(॥)Pcs contributes to the bathochromic shift of maximum absorption, which is relevant for the activation of the PS in deeper tissues. Moreover, this modification also influences the overall flexibility of the macrocyclic core and results in different behaviour towards HSA. Density functional theory calculations have been carried out to substantiate the effect of the peripheral environment on the photophysical characteristics and geometry of the molecules.
\end{abstract}

\section{Introduction}

Photodynamic therapy (PDT) is a powerful light-driven therapeutic modality for the treatment of cancerous diseases ${ }^{1}$ as well as nononcological disorders ${ }^{2}$ and is based on the localized generation of reactive oxygen species (ROS). It requires the use of a photosensitizer (PS), which is non-reactive in the absence of light, and able to induce damage upon irradiation at a specific wavelength. However, currently available photoactive materials are not optimal; there is a continuous search for new PSs that have enhanced solubility, favorable pharmacokinetic behavior and rapid systemic clearance. ${ }^{3}$ Many of these features are strongly related to the PS's hydrophilic/hydrophobic properties. Although hydrophobic PSs could efficiently permeate cell membranes, thereby enhancing the therapeutic efficiency, their tendency to aggregate in aqueous media and accumulate in the patient's body, inducing prolonged

\footnotetext{
${ }^{a}$ European Institute for Molecular Imaging, Waldeyerstr.15, 48149 Münster, Germany. E-mail: anzhela.galstyan@wwu.de

${ }^{b}$ Physikalisches Institut and CeNTech, Westfälische Wilhelms-Universität Münster, Heisenbergstrasse 11, 48149 Münster, Germany

'Department of Nuclear Medicine, University Hospital Münster,

Albert-Schweitzer-Campus 1, 48149 Münster, Germany

${ }^{d}$ DFG EXC 1003 'Cells in Motion' Cluster of Excellence, University of Münster, Germany

$\dagger$ Electronic supplementary information (ESI) available: Experimental procedures, spectral data and the full DFT reference list. See DOI: 10.1039/c6tb01341d
}

light sensitivity, makes them non-ideal for PDT treatment. ${ }^{4}$ In contrast, amphiphilic PSs have balanced solubility behavior and are able to cross the lipid barrier. ${ }^{5}$ Studies have demonstrated that PSs with two adjacent hydrophilic groups were more active than derivatives with two groups on the opposite side of the chromophore. ${ }^{6}$ As a consequence of low toxicity and improved pharmacokinetics, carbohydrate conjugates are widely used in drug development. ${ }^{7}$ Since a distinctive feature of many effective PSs is a highly hydrophobic macrocycle, conjugation of sugar molecules offers a unique possibility of tuning the hydrophilic-hydrophobic balance of the PS. In fact, studies suggest that conjugation of at least four sugar moieties to a PS is essential to achieve water solubility. ${ }^{8}$ Several in vitro studies on the impact of PS amphiphilicity on photocytoxicity were carried out using carbohydrate-linked asymmetric phthalocyanines, indicating that the number and position (peripheral vs. non-peripheral) of the substituents have a great influence on their activity. ${ }^{9}$ However, not many studies have examined cases where more than one carbohydrate unit is grafted onto a spacer that is connected to the phthalocyanine macrocycle. ${ }^{10}$ Thus, in the present study we employed a linear malto-oligosaccharide containing six glycosyl units linked through $\alpha-1,4$-glycosidic bonds to functionalize tailor made $\mathrm{Zn}$ (II)Pcs.

For effective PDT treatment and fluorescence imaging a PS should exhibit strong absorption in the near infrared region, corresponding to the "therapeutic window". As a result of the intrinsic absorption of endogenous chromophores such as 
hemoglobin and melanin, light flow at the wavelengths less than $550 \mathrm{~nm}$ is very low. ${ }^{11}$ However, it almost doubles from $550 \mathrm{~nm}$ to $630 \mathrm{~nm}$ and doubles again to $700 \mathrm{~nm} .{ }^{12}$ Phthalocyanine derivatives are shown to be efficient theranostic agents due to their intense red light absorption ${ }^{13}$ and the possibility of tuning their photophysical properties via variations of substituents on the macrocyclic core. For instance, Kobayashi and co-workers demonstrated that the introduction of group 16 elements at the $\alpha$ position of the Pc macrocycle contributes to red shifted absorption and fluorescence. ${ }^{14}$ Although intensive research has been done on this subject, many structure-activity relationships are not completely understood.

In this work, we synthesize low symmetry hydroxy- and mercaptopyridine substituted Zn(II)Pc-maltohexaose conjugates and studied the effect of the bridging atom (O- $v s$. S-) on the PS's geometry, photophysical features and in vitro phototoxicity against human melanoma cells.

\section{Results and discussion}

We elected to synthesize low symmetry Zn(II)Pcs, since the disruption of molecular symmetry is known to account for the increased solubility of Pcs. ${ }^{15}$ The syntheses were carried out via cyclotetramerization of substituted phthalonitriles, starting from 3-nitrophthalonitrile, which was converted into the 2-pyridoxy, 2-mercaptopyridine or 3-(2-\{2-[2-(2-hydroxyethoxy)ethoxy]ethoxy\} ethoxy)phthalonitrile by aromatic nucleophilic substitution in the presence of $\mathrm{K}_{2} \mathrm{CO}_{3}$ (Scheme 1). The corresponding phthalonitriles were statistically condensed employing 1,8-diazabicyclo[5.4.0.]undec-7-ene (DBU) and anhydrous zinc acetate in refluxing 1-pentanol under an argon atmosphere, yielding a mixture of $\mathrm{A}_{4}$ and $\mathrm{A}_{3} \mathrm{~B}$-type $\mathrm{Zn}$ (II)Pcs. ${ }^{16}$ A 5-fold excess of 2-pyridoxy- or 2-mercaptopyridine ensured a relatively high yield of the low symmetry product. The mixed products were separated and isolated by chromatographic techniques. Mesylation of the hydroxyl group followed by nucleophilic substitution by sodium azide led to the azido functionalized Pcs, which were further clicked with alkyne functionalized maltohexaose unit resulting in the formation of $\mathrm{Zn}$ (II)Pcs bearing pyridoxy- (Pc1-p) or mercaptopyridine (Pc2-p) substituents at non-peripheral positions. Removal of the acetyl groups on the sugar units under mild Zemplèn deprotection conditions ( $\mathrm{NaOMe}$ in $\mathrm{MeOH} / \mathrm{CH}_{2} \mathrm{Cl}_{2}$ ) gave the corresponding water-soluble maltohexaose conjugated Zn(II)Pcs Pc1-d and Pc2-d.

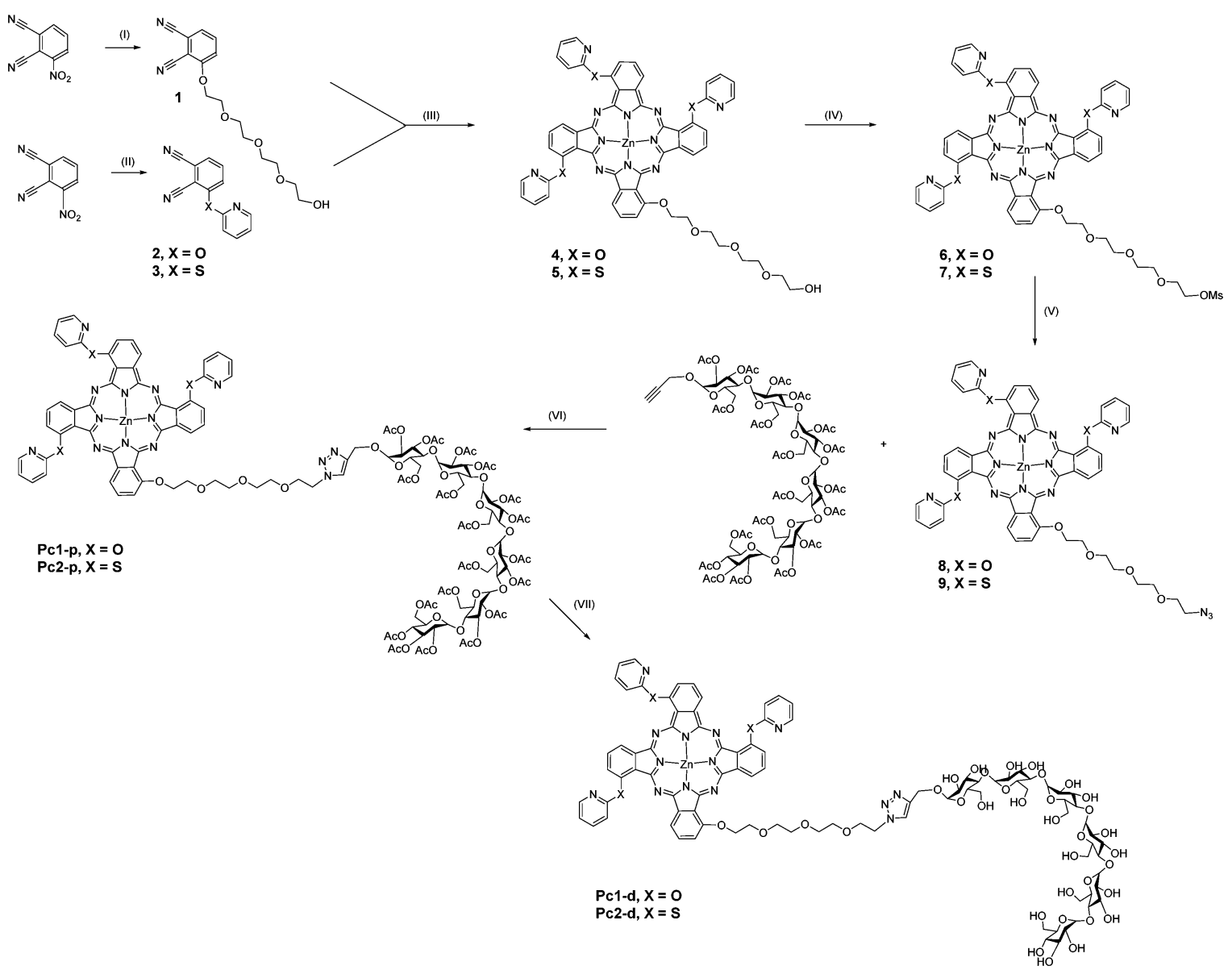

Scheme 1 Synthetic pathway towards Pc1-p, Pc2-p, Pc1-d and Pc2-d. (I) Tetraethylene glycol, $\mathrm{K}_{2} \mathrm{CO}_{3}, \mathrm{DMF}, \mathrm{rt}$; (II) 2-hyroxypyridine, $\mathrm{K}_{2} \mathrm{CO}_{3}, \mathrm{DMF}, \mathrm{rt}$; (III) $\mathrm{Zn}(\mathrm{OAC})_{2}, 1$-pentanol, $\mathrm{DBU}, 140{ }^{\circ} \mathrm{C}, 18 \mathrm{~h}$; (IV) methanesulfonyl chloride, trimethylamine, dichloromethane, $0{ }^{\circ} \mathrm{C} \rightarrow \mathrm{rt}, 5 \mathrm{~h}$; (V) NaN $3, \mathrm{DMF}, 100{ }^{\circ} \mathrm{C}, 18 \mathrm{~h}$; (VI) $\mathrm{CuSO}_{4} \cdot 5 \mathrm{H}_{2} \mathrm{O}$, sodium ascorbate, $\mathrm{CH}_{2} \mathrm{Cl}_{2} / \mathrm{H}_{2} \mathrm{O} 1: 1, \mathrm{rt}, 18 \mathrm{~h}$; (VII) $\mathrm{NaOMe}, \mathrm{MeOH}, \mathrm{CH}_{2} \mathrm{Cl}_{2}, \mathrm{rt}, 3 \mathrm{~h}$. 
Table 1 The photophysical parameters of Pc1-p, Pc1-d, Pc2-p and Pc2-d

\begin{tabular}{|c|c|c|c|c|c|c|c|c|}
\hline \multirow[b]{2}{*}{ Compound (solvent) } & \multirow[b]{2}{*}{$\lambda_{\mathrm{abs}} / \mathrm{nm}(\log 10 \varepsilon)$} & \multirow[b]{2}{*}{$\lambda_{\mathrm{em}} / \mathrm{nm}$} & \multirow[b]{2}{*}{$\Phi_{\mathrm{F}}{ }^{a}$} & \multirow[b]{2}{*}{$\Phi_{\Delta}{ }^{b}$} & \multirow[b]{2}{*}{$\tau_{\mathrm{F}} / \mathrm{ns}$} & \multirow[b]{2}{*}{$\log P_{\mathrm{o} / \mathrm{w}}$} & \multicolumn{2}{|c|}{ HSA binding } \\
\hline & & & & & & & $K_{\mathrm{a}}\left(\mathrm{M}^{-1}\right)$ & $n$ \\
\hline Pc1-p $\left(\mathrm{CHCl}_{3}\right)$ & $336(4.71), 618(4.47), 684(5.15)$ & 700,760 & 0.13 & 0.47 & 2.75 & & & \\
\hline Pc1-d (DMF) & $329(4.36), 619(4.09), 686(4.78)$ & $697,767_{\mathrm{sh}}$ & 0.16 & 0.45 & 2.51 & & & \\
\hline Pc1-d $\left(\mathrm{H}_{2} \mathrm{O}\right)$ & $320(4.41), 644(4.32), 685(4.33)$ & $712,791_{\mathrm{sh}}$ & 0.02 & n. d. & 2.46 & -0.51 & $0.16 \times 10^{5}$ & 0.86 \\
\hline Pc2-p $\left(\mathrm{CHCl}_{3}\right)$ & $337(4.74), 630(4.50), 700(5.18)$ & 715,784 & 0.14 & 0.49 & 2.84 & - & - & - \\
\hline Pc2-d (DMF) & $334(4.47), 626(4.35), 697(5.05)$ & $709,781_{\mathrm{sh}}$ & 0.17 & 0.53 & 2.44 & & & \\
\hline Pc2-d $\left(\mathrm{H}_{2} \mathrm{O}\right)$ & $334(4.41), 654(4.41), 704(4.44)$ & $723,800_{\mathrm{sh}}$ & 0.02 & n. d. & 2.35 & -0.47 & $2.47 \times 10^{5}$ & 1.05 \\
\hline
\end{tabular}

Newly synthesised Zn(II)Pcs were characterized by NMR, MALDI-MS, HRMS, UV-Vis and FT-IR spectral methods. ${ }^{1} \mathrm{H}$ NMR spectra of Pc1-p and Pc2-p in $\mathrm{CD}_{2} \mathrm{Cl}_{2}$ show broad chemical shifts likely due to the self-aggregation at the NMR concentration as well as the presence of positional isomers. Nevertheless, the integrated intensities of signals correspond to the number of hydrogens in the compounds. The mass spectra of all compounds show the $\mathrm{m} / \mathrm{z}$ of molecular ions in accordance with molecular formulas of Pcs (ESI $\dagger$ ). FT-IR spectral analysis results were also consistent with the proposed structures. Deprotection of the carbohydrate moieties was confirmed by the disappearance of the peaks at $1750 \mathrm{~cm}^{-1}$ and $1741 \mathrm{~cm}^{-1}$ in FT-IR spectra, which correspond to the acetylated groups, and the appearance of a broad peak between 3100 and $3500 \mathrm{~cm}^{-1}$ due to the $\mathrm{OH}$ stretching.

The photophysical behaviour of Zn(II)Pcs was studied by UV-vis, as well as steady-state and time-resolved fluorescence spectroscopy; the data are summarized in Table 1 along with Fig. 1 and Fig. S1-S10 of the ESI. $\dagger$ The electronic absorption spectra of Pc1-d and Pc2-d containing the deprotected form of maltohexaose were acquired in $N, N$-dimethylforamide (DMF) and are very similar to that of the corresponding $\mathrm{Zn}$ (II)Pcs containing the protected form of maltohexaose Pc1-p and Pc2-p acquired in chloroform $\left(\mathrm{CHCl}_{3}\right)$. In both cases monomeric behaviour was evidenced by single well-defined Q-bands peaking at $684 \mathrm{~nm}$ and $686 \mathrm{~nm}$ for Pc1-p and Pc1-d, and $700 \mathrm{~nm}$ and $697 \mathrm{~nm}$ for Pc2-p and Pc2-d, respectively (Fig. 1a and Fig. S1, ESI $\dagger$ ). However, the spectra recorded in water media differ remarkably for both conjugates. Bands in the near-infrared region are wide with lower molar absorption coefficients, indicative of coaxial H-type aggregation of substituted phthalocyanines. ${ }^{17}$ Nevertheless, probe aggregation in water solution does not limit
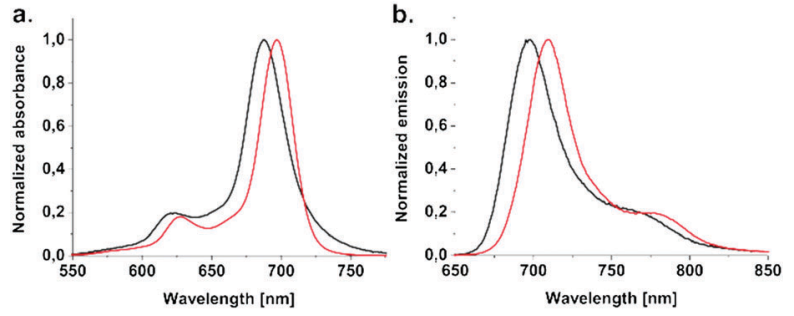

Fig. 1 (a) Normalized absorption and (b) emission ( $\lambda_{\text {exc }}=620 \mathrm{~nm}$ ) spectra of Pc1-d and Pc2-d in DMF. their application as PDT agents, since it is well known that Pcs are found to undergo deaggregation upon binding to proteins like human serum albumin (HSA, vide infra) or when they are taken up by cells. ${ }^{18}$

As expected, emission maxima of studied Pcs are also affected by the nature of the bridging heteroatom (Fig. 1b). The impact of this heteroatom on the photophysical properties was analysed and compared for both protected and deprotected forms of the maltohexaose conjugated Zn(II)Pcs. When the bridging heteroatom consisted of a better electron-donor, such as the sulfur atom in Pc2-p compared to the oxygen atom in Pc1-p, a $15 \mathrm{~nm}$ red shift of the emission maxima from $700 \mathrm{~nm}$ to $715 \mathrm{~nm}$ was detected. A similar trend was also observed for Pc2-d and Pc1-d; the emission maximum was red shifted by $12 \mathrm{~nm}$ from $697 \mathrm{~nm}$ to $709 \mathrm{~nm}$. The fluorescence decay profiles (Fig. S3-S8, ESI $\dagger$ ) obtained for all compounds are characterized by an exponential decay process with a lifetime range of 2.35$2.84 \mathrm{~ns}$, implying that only a single molecular species is present in the solution.

The absolute fluorescence quantum yields $\left(\Phi_{\mathrm{F}}\right)$ of Pc1-p and Pc2-p in $\mathrm{CHCl}_{3}$ determined in an integrating sphere system were found to be 0.13 and 0.14 , respectively. The $\Phi_{\mathrm{F}}$ values for Pc1-d and Pc2-d measured in DMF were 0.16 and 0.17 slightly higher than that of the corresponding Zn(II)Pcs containing the protected forms of maltohexaose. To evaluate the photosensitising efficiency of these compounds, their singlet oxygen quantum yields $\left(\Phi_{\Delta}\right)$ were determined, using the method of direct measurement of emission from singlet oxygen at the peak of $1270 \mathrm{~nm}$ as a function of absorption using tetra-t-butylphthalocyaninato zinc(II) as a reference (Fig. S9 and S10, ESI $\dagger$ ). In DMF solution Pc2-d was found to generate singlet oxygen more efficiently $\left(\Phi_{\Delta}=0.53\right)$ compared to Pc1-d $\left(\Phi_{\Delta}=0.45\right)$. This can be attributed to the enhanced rate of intersystem crossing caused by the heavy-atom effect of sulfur. ${ }^{19}$ Low yields of photogenerated singlet oxygen in aqueous media prevented a quantitatively meaningful determination for Pc1-d and Pc2-d. However, photophysical and photochemical properties of PSs are known to be affected by interaction with the biological environment. As expected, the UV-vis spectral analysis of Pc1-d and Pc2-d show an increase of absorbance in the presence of HSA as well as an increase in the proportion between the monomeric (low energy) and aggregated (high energy) bands in both cases (Fig. S12, ESI $\dagger$ ). Sharpening of absorption signals at $685 \mathrm{~nm}$ for Pc1-d and $704 \mathrm{~nm}$ for Pc2-d is a clear indication of the suppression of aggregation. 
These interactions can decrease the nonradioative relaxation of the PS at dark energy traps, with subsequent enhancement of the photoreactivity of the dye.

Density functional theory (DFT) and time-dependent density functional theory (TD-DFT) calculations were carried out to obtain the geometric structures of Pcs and to ascertain the HOMO (highest occupied molecular orbital)-LUMO (lowest unoccupied molecular orbital) energy level differences. It is well established that among the four possible symmetry isomers of the 1, 8, 15 and 22 substituted Pcs the $C_{4 \mathrm{~h}}$ isomer is the most energetically stabile due to the steric bulk of the substituents. ${ }^{20}$ Hence, we only considered a $C_{4 \mathrm{~h}}$-like ligand arrangement. The bulky polyethyleneglycol-hexa-maltosyl group was replaced with the-OMe substituent in order to save computational resources. The geometry at its ground state $\left(\mathrm{S}_{0}\right)$ was optimized using the hybrid B3LYP function with a $6-311 G^{*}$ basis set. Geometry optimizations were performed on each complex from an initial geometry where the pyridine ligands were perpendicular to the Pc macrocycle considering all the possible rotational isomers.

The optimized geometries indicate that (i) Zn(II) has a perfect coplanar geometry with the macrocyclic ring, which also displays a planar geometry, (ii) the most energetically stable isomer was found be the one with pyridines in an all-trans orientation with respect to the Pc ring and (iii) in the model system Pc1-m pyridines are oriented almost perpendicular to the Pc-ring with tilted angles around $80^{\circ}$, whereas in Pc2-m the orientation of pyridine substituents are roughly coplanar with tilt angles around $16^{\circ}$ (Fig. 2a and b).

Inspection of the molecular orbital plots indicate that in both model compounds Pc1-m and Pc2-m the first two excited states responsible for the observation of $\mathrm{Q}_{\mathrm{x}}$ and $\mathrm{Q}_{\mathrm{y}}$ bands resemble pure HOMO $(\pi \mathrm{MO}) \rightarrow$ LUMO $\left(\pi^{*} \mathrm{MO}\right)$ and HOMO $(\pi \mathrm{MO}) \rightarrow$ LUMO+1 ( $\left.\pi^{*} \mathrm{MO}\right)$ transitions (Fig. 2c and Table 2). Unlike LUMOs, HOMOs are delocalized over the entire macrocycle and, in the case of Pc2-m, have a significant contribution from the non-peripheral

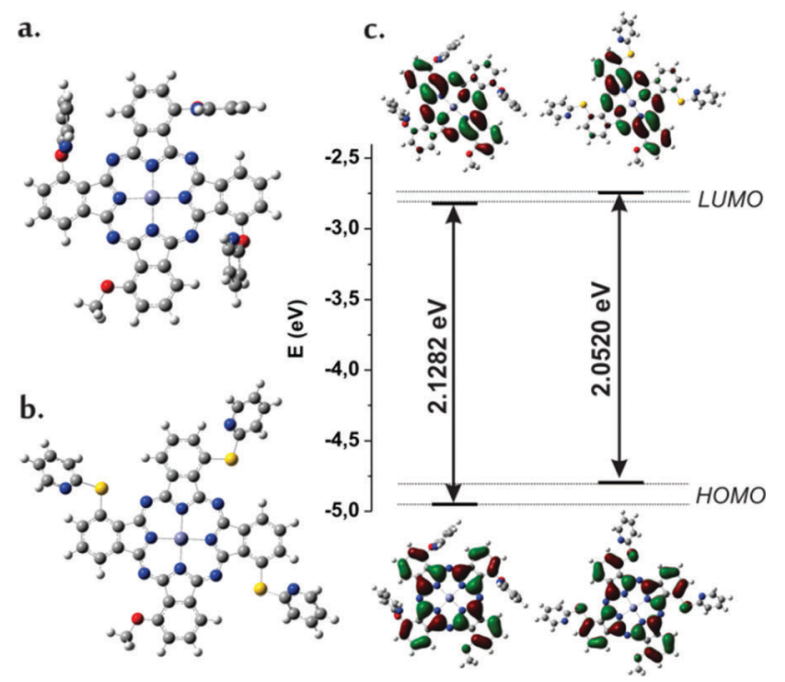

Fig. 2 Optimized structures of model compounds Pc1-m (a) and Pc2-m (b) highlighting the tilt in the pyridine ligands. (c) Energy levels of frontier MOs and their contour plots obtained from TD-DFT calculations.
Table 2 Energy differences predicted in the TD-DFT calculations: $\Delta\left(E_{\mathrm{L}}-E_{\mathrm{H}}\right)$, calculated excited wavelength $(\lambda)$, oscillator strength $(f)$ and composition

\begin{tabular}{lllll}
\hline Compound & $\Delta\left(E_{\mathrm{L}}-E_{\mathrm{H}}\right)(\mathrm{eV})$ & $\lambda(\mathrm{nm})$ & $f$ & $\operatorname{Composition}^{a}(\%)$ \\
\hline Pc1-m & 2.1282 & 616.22 & 0.4314 & $\mathrm{H} \rightarrow \mathrm{L}+1(67)$ \\
& & 614.16 & 0.4687 & $\mathrm{H} \rightarrow \mathrm{L}(67)$ \\
& & & $\mathrm{H} \rightarrow \mathrm{L}+1(18)$ \\
Pc2-m & 2.0520 & 644.05 & 0.5200 & $\mathrm{H} \rightarrow \mathrm{L}+1(70)$ \\
& & 641.00 & 0.5314 & $\mathrm{H} \rightarrow \mathrm{L}(21)$ \\
& & & & $\mathrm{H} \rightarrow \mathrm{L}+1(66)$
\end{tabular}

${ }^{a} \mathrm{H}, \mathrm{L}$ and $\mathrm{L}+1$ denote the HOMO, the LUMO and LUMO +1 , respectively.

atoms of sulfur. When sulfur is present instead of oxygen, there is larger destabilization of the HOMO energy, leading to a smaller HOMO-LUMO gap. Thus, the estimated $\Delta\left(E_{\text {LUMO }}-E_{\text {HOMO }}\right)$ value for Pc2-m (2.05 eV) is smaller than that of Pc1-m $(2.13 \mathrm{eV})$ in accordance with the relative Q-band positions of the Pc1-d and Pc2-d in UV-vis spectra.

The oscillator strengths calculated for HOMO-LUMO and HOMO-LUMO+1 transitions in Pc1-m (0.47 and 0.43) are found to be lower than those for Pc2-m (0.53 and 0.52), which validates the results obtained experimentally. The computed excitation energies and main configurations in a vacuum are reported in Table 2 and Table S1 of the ESI. $\dagger$

The mode of action and therapeutic efficiency of PSs are highly dependent on their sufficient delivery to a tumour region and their uptake by the target cells. ${ }^{21}$ Human serum albumin (HSA) is the most abundant protein in the circulatory system (for healthy individuals, the levels of HSA are about $50 \mathrm{~g} \mathrm{~L}^{-1}$ $(0.75 \mathrm{mM})){ }^{22}$ It can bind and transport various ligands to a tumour site by the so-called enhanced permeation and retention (EPR) effect, which results from the non-mature neovessels of a growing tumor. ${ }^{23}$ It has been reported that PS molecules showing high binding affinity at the hydrophobic pocket of HSA exhibit efficient PDT activity. ${ }^{24}$ To evaluate the possibility of HSA acting as a carrier to deliver Pc1-d and Pc2-d, we studied their interaction with HSA via fluorescence spectroscopy. As a consequence of the interaction of the Pc ring with the specific amino acids near the binding site, upon addition of Pc1-d and Pc2-d a concentration dependent quenching of the intrinsic fluorescence of HSA was observed (Fig. 3). Compound Pc2-d showed stronger HSA binding than Pc1-d, as indicated by measured binding constants $\left(2.47 \times 10^{5} \mathrm{M}^{-1}\right.$ vs. $\left.0.16 \times 10^{5} \mathrm{M}^{-1}\right)$. Most likely, the structural flexibility of the Pc containing the S-bridged pyridines contributed to the better complementarity with the binding site, indicating that certain structural characteristics could strongly affect the binding efficiency and, consequently, the overall effect of PDT.

The nature of the conjugated moiety can affect the kinetics and efficiency of PS binding to cells, as well as its distribution among the subcellular components via modulation of the hydrophilic-hydrophobic balance..$^{25,26}$ The octanol/water partition coefficient $\left(\log P_{\mathrm{o} / \mathrm{w}}\right)$ is a quantitative parameter that describes the behaviour of molecules in polar and nonpolar phases and correlates fairly well with the efficiency of uptake through 
a.
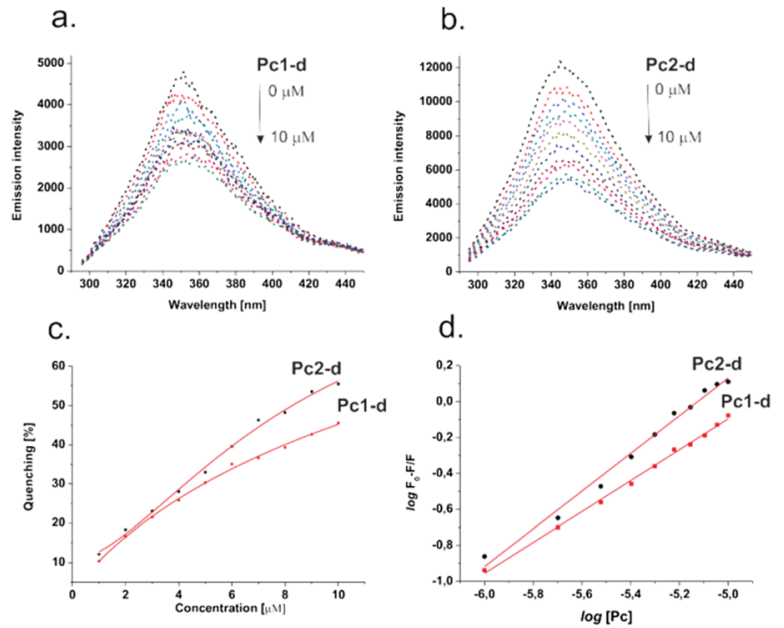

Fig. 3 Fluorescence emission spectral changes of HSA (50 $\mu \mathrm{M})$ upon the addition of varying concentrations $(0-10 \mu \mathrm{M})$ of (a) Pc1-d and (b) Pc2-d, (c) emission quenching curves and (d) logarithmic relationship of fluorescence quenching.

membranes. Generally, a drug with a $\log P_{\mathrm{o} / \mathrm{w}}$ between 0 and 3 has an optimal balance to cross the cell membrane; however, a $\log P_{\mathrm{o} / \mathrm{w}}$ below 0 is desired for injectable drugs. ${ }^{27}$ The $\log P_{\mathrm{o} / \mathrm{w}}$ values of Pc-1d and Pc-2d were determined by UV-vis spectroscopy (Fig. S11, ESI $\dagger$ ) by saturating equal volumes of 1-octanol and water with the $\mathrm{Zn}$ (II)Pcs. Estimated values of -0.51 (Pc1-d) and -0.47 (Pc2-d) suggest that these Pcs could feasibly be taken up via absorptive endocytosis. ${ }^{28}$

The photocytotoxicity of Pc1-d and Pc2-d was investigated against human malignant melanoma, one of the most dreaded and therapy unresponsive skin cancer worldwide. ${ }^{29}$ To assess their photokilling efficiency COLO 818 cells were treated with $\mathrm{Zn}$ (II)Pcs in the concentration range of $1-10 \mu \mathrm{g} \mathrm{mL} \mathrm{m}^{-1}$,

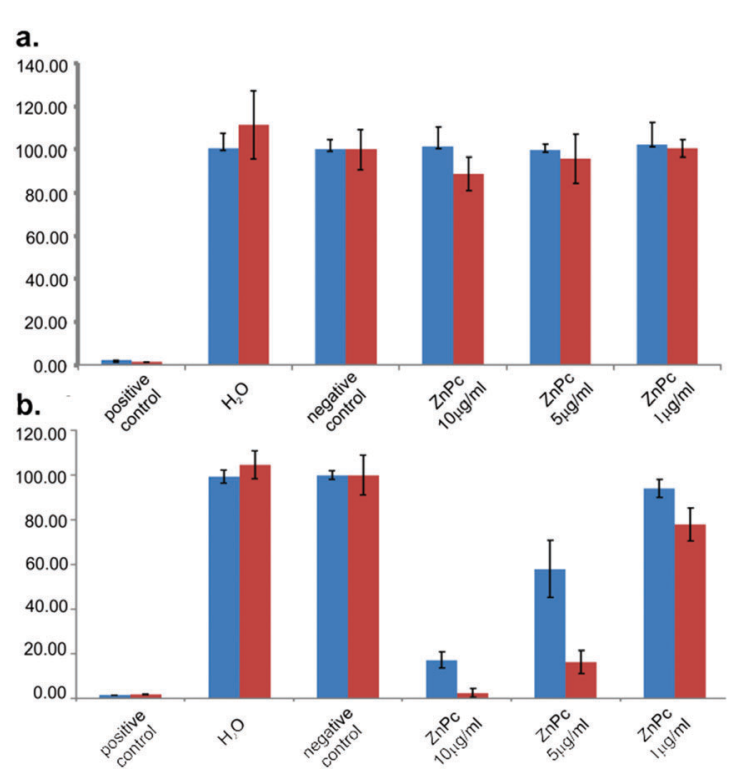

Fig. 4 (a) Dark cytotoxicity and (b) photocytotoxicity of Pc1-d (blue bars) and Pc2-d (red bars) in COLO 818 cells, mean \pm SD, $n=3$. followed by irradiation with red light at $\lambda>610 \mathrm{~nm}$ with $10 \mathrm{~mW} \mathrm{~cm}^{-2}$ light flow for one hour, and a total radiant exposure of $36 \mathrm{~J} \mathrm{~cm}^{-2}$. Cellular survival was determined $24 \mathrm{~h}$ after illumination using the CellTiter-Flour ${ }^{\mathrm{TM}}$ Cell Viability Assay (Promega $\mathrm{GmbH}$ ).

As shown in Fig. 4a, without light irradiation no toxicity was found for both samples even at the highest concentration $\left(10 \mu \mathrm{g} \mathrm{mL}^{-1}\right)$, indicating good biocompatibility of the $\mathrm{Zn}$ (II)Pc conjugates. Likewise, irradiation alone did not induce cytotoxicity. Fig. $4 \mathrm{~b}$ shows the cell survival ratio as a function of the concentration after irradiation (data are summarized in Table S2, ESI $\dagger$ ). When Pc1-d was used as a PS, significant cell death was observed at a concentration of $10 \mu \mathrm{g} \mathrm{mL} \mathrm{m}^{-1}$; the surviving fraction was $17.28 \pm 3.60 \%$. However, at $5 \mu \mathrm{g} \mathrm{mL}^{-1}$ and $1 \mu \mathrm{g} \mathrm{mL} \mathrm{mL}^{-1}$, cell viability increased to $57.92 \pm 12.74 \%$ and $93.97 \pm 4.06 \%$, respectively. Similarly, Pc2-d showed clear concentration-dependent photocytotoxicity, with substantially higher photodynamic killing under the same conditions (surviving fractions: $2.43 \pm 1.95 \%, 16.38 \pm$ $5.21 \%$ and $77.98 \pm 7.39$ for $10 \mu \mathrm{g} \mathrm{mL}^{-1}, 510 \mu \mathrm{g} \mathrm{mL}{ }^{-1}$ and $1 \mu \mathrm{g} \mathrm{mL}{ }^{-1}$ respectively). This could be attributed to the higher rate of ${ }^{1} \mathrm{O}_{2}$ generation of Pc2-d compared to Pc1-d and is consistent with the photophysical characteristics of the compound. As observed via a light microscope, the cell death process was accompanied by significant morphological changes, including cell rounding and shrinkage (Fig. S14, ESI $\dagger$ ).

\section{Conclusions}

In summary, we designed and prepared two new amphiphilic $\mathrm{Zn}$ (II)phthalocyanine-maltohexaose conjugates and studied the influence of the peripheral environment of the Pc on its photosensitizing properties. This study represents the first example where O- and S-linked Pc derivatives are compared using photophysical, theoretical and in vitro biological studies. Our results indicate that the replacing oxygen with sulfur not only contributes to the bathochromic shift of the absorption maxima, but it also increases the quantum yield of the singlet oxygen formation. TD-DFT computations verified the extra redshifted $\mathrm{Q}$ band of Pc2-d. Furthermore, fluorescence studies estimated the binding ability of $\mathrm{Zn}$ (II)Pcs to the most abundant protein in human blood HSA, which can serve as a shuttle for PS delivery. The presence of sulfur as the bridging atom in Pc2-d (compared to oxygen in Pc1-d) gives the molecule more flexibility and results in a higher binding affinity. Overall, this study highlights the importance of studying structure-activity relationships and paves the way for the qualitative improvement of PDT fostering clinical applications.

\section{Experimental section}

\section{General information}

Synthetic procedures were carried out under a dry argon atmosphere, unless otherwise specified. All reagents and solvents were purchased at the highest commercial quality available and used without further purification. Mili-Q water was used throughout 
the experiments. Column chromatography was carried out on silica gel Merck-60 (230-400 mesh, $60 \AA$ ), and TLC on aluminum sheets pre-coated with silica gel 60 F254 (E. Merck). NMR spectra were recorded on an ARX 300 or an AMX 400 from Bruker Analytische Messtechnik (Karlsruhe, Germany) spectrometer at a constant temperature of $298 \mathrm{~K} .{ }^{1} \mathrm{H}$ NMR: chemical shifts $\delta$ are given relative to TMS $(d=0)$ and referenced to the solvent signal. Electrospray ionization (ESI) mass spectra were recorded on a Bruker Daltonics (Bremen, Germany) MicroTof with loop injection. MALDI-TOF MS was recorded using a Bruker Reflex III spectrometer. 3-(2-\{2-[2-(2-Hydroxyethoxy)ethoxy] ethoxy $\}$-ethoxy)phthalonitrile (1) ${ }^{30} 3$-(2-pyridyloxy)phthalonitrile (2) and 3-(2-mercaptopyridine)phthalonitrile $(3)^{31}$ were synthesized and purified according to the published methods.

Synthesis of 1,8(11),15(18)-tri-(2-pyridyloxy)-23(24)-3-(2-\{2-[2(2-hydroxyethoxy)-ethoxy]ethoxy\}ethoxy)phthalocyaninato zinc(II) (4). 3-(2-\{2-[2-(2-Hydroxyethoxy)ethoxy]ethoxy\}-ethoxy)phthalonitrile (1) (318 mg, $1 \mathrm{mmol}$ ), 3-(2-pyridyloxy)-phthalonitrile (2) (1095 mg, $5 \mathrm{mmol})$, DBU $(0.1 \mathrm{~mL}, 0.63 \mathrm{mmol})$ and $\mathrm{Zn}(\mathrm{OAc})_{2}$ (343 mg, $2 \mathrm{mmol}$ ) were refluxed in dry pentanol $(10 \mathrm{~mL})$ for $24 \mathrm{~h}$ under an argon atmosphere. Then, the reaction mixture was cooled to room temperature and poured into $n$-hexane. The blue-green solid product was precipitated and collected by filtration. The crude product (4) was purified over a silica gel column using a chloroform : methanol 9:1 mixture as an eluent. Yield: $188 \mathrm{mg}$ (18\%). UV-Vis $\left(\mathrm{CHCl}_{3}\right) \lambda_{\max } \mathrm{nm}, 335,619,685$. ${ }^{1} \mathrm{H}$ NMR (300 MHz, $\mathrm{CD}_{2} \mathrm{Cl}_{2}$ ): $\delta$, ppm: 8.97-6.33 (m, 24H, Pc-H and Py-H), 4.61-3.29 (m, 16H, $\left.\mathrm{CH}_{2}\right)$. MALDI-MS $m / z$ : calcd for $\mathrm{C}_{55} \mathrm{H}_{41} \mathrm{~N}_{11} \mathrm{O}_{8} \mathrm{Zn}$ 1047.24; found: 1047.25. HRMS $\mathrm{m} / \mathrm{z}$ calcd for $\mathrm{C}_{55} \mathrm{H}_{41} \mathrm{~N}_{11} \mathrm{O}_{8} \mathrm{ZnH}$ 1048.2504; found: 1048.2511.

Synthesis of 1,8(11),15(18)-tri-(2-mercaptopyridine)-23(24)-3(2-\{2-[2-(2-hydroxyethoxy)-ethoxy]ethoxy\}ethoxy)phthalocyaninato zinc(II) (5). 3-(2-\{2-[2-(2-Hydroxyethoxy)ethoxy]ethoxy\}-ethoxy)phthalonitrile (1) (318 mg, $1 \mathrm{mmol}), 3$-(2-mercaptopyridine) phthalonitrile (2) (1175 mg, $5 \mathrm{mmol}$ ), DBU (0.1 mL, $0.63 \mathrm{mmol}$ ) and $\mathrm{Zn}(\mathrm{OAc})_{2}(114.4 \mathrm{mg}, 0.63 \mathrm{mmol})$ were refluxed in dry pentanol $(3 \mathrm{~mL})$ for $24 \mathrm{~h}$ under an argon atmosphere. Then, the reaction mixture was cooled to room temperature and poured into $n$-hexane. The green solid product was precipitated and collected by filtration. The crude product (5) was purified over a silica gel column using a chloroform: methanol 9:1 mixture as an eluent. Yield: $252 \mathrm{mg}(23 \%)$. UV-Vis $\left(\mathrm{CHCl}_{3}\right) \lambda_{\max } \mathrm{nm}, 338,630$, 699. ${ }^{1} \mathrm{H}$ NMR (300 MHz, $\left.\mathrm{CD}_{2} \mathrm{Cl}_{2}\right): \delta$, ppm: 9.12-6.81 (m, 24H, Pc-H and Py-H), 4.26-3.25 (m, 16H, $\mathrm{CH}_{2}$ ). MALDI-MS $\mathrm{m} / \mathrm{z}$ : calcd for $\mathrm{C}_{55} \mathrm{H}_{41} \mathrm{~N}_{11} \mathrm{O}_{5} \mathrm{~S}_{3} \mathrm{Zn}$ 1095.18: found: 1095.12. HRMS $\mathrm{m} / \mathrm{z}$ calcd for $\mathrm{C}_{55} \mathrm{H}_{41} \mathrm{~N}_{11} \mathrm{O}_{5} \mathrm{~S}_{3} \mathrm{ZnH}$ 1096.1819; found: 1096.1859.

Synthesis of 1,8(11),15(18)-tri-(2-pyridyloxy)-23(24)-3-(2-\{2-[2(2-azodoethoxy)-ethoxy]ethoxy\}ethoxy)phthalocyaninato zinc(II) (8). Compound 4 (157 mg, $0.15 \mathrm{mmol}$ ) was dissolved in dichloromethane $(30 \mathrm{~mL})$ in the presence of trimethylamine $(52 \mu \mathrm{L}$, $0.375 \mathrm{mmol}$ ) and cooled down to $\sim 0{ }^{\circ} \mathrm{C}$ in an ice bath. Methane sulfonyl chloride $(18 \mu \mathrm{L}, 0.225 \mathrm{mmol}$ ) was added drop-wise to the solution and the mixture was allowed to warm to room temperature with continuous stirring for $30 \mathrm{~min}$. The resulting solution was washed with water and the dichloromethane phase was dried using anhydrous $\mathrm{Na}_{2} \mathrm{SO}_{4}$. The solvent was removed to give the mesylated phthalocyanine $\mathbf{6}$, which was used without purification. 6 and $\mathrm{NaN}_{3}(39 \mathrm{mg}, 0.6 \mathrm{mmol}$ ) were stirred in DMF $(15 \mathrm{~mL})$ at $100{ }^{\circ} \mathrm{C}$ for $18 \mathrm{~h}$. After completion, the reaction mixture was poured into $\mathrm{H}_{2} \mathrm{O}(50 \mathrm{~mL})$ and the green precipitate filtered, dissolved in $\mathrm{CH}_{2} \mathrm{Cl}_{2}(50 \mathrm{~mL})$ and washed with $\mathrm{H}_{2} \mathrm{O}$. After drying over $\mathrm{Na}_{2} \mathrm{SO}_{4}$ and concentrating, the crude product was purified by silica gel column chromatography, using a chloroform/methanol 95:5 mixture as an eluent, leading to $52 \mathrm{mg}$ of compound 8. Yield: $32 \%$. UV-Vis $\left(\mathrm{CHCl}_{3}\right) \lambda_{\max } / \mathrm{nm}$ 336, 618, 685. ${ }^{1} \mathrm{H}$ NMR $\left(300 \mathrm{MHz}, \mathrm{CD}_{2} \mathrm{Cl}_{2}\right): \delta$, ppm: 8.99-6.59 (m, $24 \mathrm{H}, \mathrm{Pc}-\mathrm{H}$ and Py-H), 4.75-3.16 (m, $\left.16 \mathrm{H}, \mathrm{CH}_{2}\right)$. MALDI-MS $m / z$ : calcd for $\mathrm{C}_{55} \mathrm{H}_{40} \mathrm{~N}_{14} \mathrm{O}_{7} \mathrm{Zn}$ 1072.25: found: 1072.18. HRMS $\mathrm{m} / \mathrm{z}$ calcd for $\mathrm{C}_{55} \mathrm{H}_{40} \mathrm{~N}_{14} \mathrm{O}_{7} \mathrm{ZnH}$ 1073.2569: found: 1073.2582; calcd for $\mathrm{C}_{55} \mathrm{H}_{40} \mathrm{~N}_{14} \mathrm{O}_{7} \mathrm{ZnNa}$ 1095.2388: found: 1095.2397.

Synthesis of 1,8(11),15(18)-tri-(2-mercaptopyridine)-23(24)-3(2-\{2-[2-(2-azodoethoxy)-ethoxy]ethoxy\}ethoxy)phthalocyaninato zinc(II) (9). Compound 5 (165 $\mathrm{mg}, 0.15 \mathrm{mmol}$ ) was dissolved in dichloromethane $(30 \mathrm{~mL})$ in the presence of trimethylamine (52 $\mu \mathrm{L}, 0.375 \mathrm{mmol}$ ) and cooled down to $\sim 0{ }^{\circ} \mathrm{C}$ in an ice bath. Methane sulfonyl chloride ( $18 \mu \mathrm{L}, 0.225 \mathrm{mmol}$ ) was added dropwise to the solution and the mixture was allowed to warm to room temperature with continuous stirring for $30 \mathrm{~min}$. The resulting solution was washed with water and the dichloromethane phase was dried using anhydrous $\mathrm{Na}_{2} \mathrm{SO}_{4}$. The solvent was removed to give the mesylated phthalocyanine 7 , which was used without purification. 7 and $\mathrm{NaN}_{3}$ (39 mg, $0.6 \mathrm{mmol}$ ) were stirred in DMF ( $15 \mathrm{~mL})$ at $100{ }^{\circ} \mathrm{C}$ for $18 \mathrm{~h}$. After completion, the reaction mixture was poured into $\mathrm{H}_{2} \mathrm{O}(50 \mathrm{~mL})$ and the green precipitate was filtered, dissolved in $\mathrm{CH}_{2} \mathrm{Cl}_{2}(50 \mathrm{~mL})$ and washed with $\mathrm{H}_{2} \mathrm{O}$. After drying over $\mathrm{Na}_{2} \mathrm{SO}_{4}$ and concentrating, the crude product was purified by silica gel column chromatography, using a chloroform/methanol 9:1 mixture as an eluent, leading to $124 \mathrm{mg}$ of compound 9. Yield: $74 \%$. UV-Vis $\left(\mathrm{CHCl}_{3}\right) \lambda_{\max } \mathrm{nm} \mathrm{337,}$ 629, 699. ${ }^{1} \mathrm{H}$ NMR (300 MHz, $\left.\mathrm{CD}_{2} \mathrm{Cl}_{2}\right): \delta$, ppm: 9.28-8.81 (m, $24 \mathrm{H}, \mathrm{Pc}-\mathrm{H}$ and Py-H), 4.92-3.26 (m, $16 \mathrm{H}, \mathrm{CH}_{2}$ ). MALDI-MS $m / z$ : calcd for $\mathrm{C}_{55} \mathrm{H}_{40} \mathrm{~N}_{14} \mathrm{O}_{4} \mathrm{~S}_{3} \mathrm{Zn}$ 1120.18: found: 1120.14 . HRMS $\mathrm{m} / \mathrm{z}$ calcd for $\mathrm{C}_{55} \mathrm{H}_{40} \mathrm{~N}_{14} \mathrm{O}_{4} \mathrm{~S}_{3} \mathrm{ZnH}$ 1121.1883: found: 1121.1893.

Synthesis of Pc1-p. To a vigorously stirred solution of 1,8(11),15(18)-tri-(2-pyridyloxy)-23(24)-3-(2-\{2-[2-(2-azodoethoxy)ethoxy]ethoxy\}ethoxy)phthalocyaninato zinc(II) (8) $(45 \mathrm{mg}$, $42 \mu \mathrm{mol})$ in $\mathrm{CH}_{2} \mathrm{Cl}_{2}(2 \mathrm{~mL})$ were added consecutively $\mathrm{CuSO}_{4}$. $5 \mathrm{H}_{2} \mathrm{O}(40 \mathrm{mg}, 160 \mu \mathrm{mol})$, (+)sodium L-ascorbate (40 mg, $200 \mu \mathrm{mol}$ ), and $\beta$-D-glucopyranose, $2,3,4,6$-tetra- $O$-acetyl- $\alpha$-D-glucopyranosyl$(1 \rightarrow 4)-O-2,3,6$-tri- $O$-acetyl- $\alpha$-D-glucopyranosyl-(1 $\rightarrow$ 4)-O-2,3,6tri- $O$-acetyl- $\alpha$-D-glucopyranosyl-( $1 \rightarrow 4)-O-2,3,6$-tri- $O$-acetyl- $\alpha$-Dglucopyranosyl-(1 $\rightarrow$ 4)-O-2,3,6-tri-O-acetyl- $\alpha$-D-glucopyranosyl$(1 \rightarrow 4)-2,3,6$-triacetate 1-(prop-2'-ynyloxy) (115 mg, $63 \mu \mathrm{mol})$. After $18 \mathrm{~h}$ of stirring in the dark at $\mathrm{rt}, \mathrm{CH}_{2} \mathrm{Cl}_{2}$ and $\mathrm{H}_{2} \mathrm{O}$ were added. The organic phase was separated, washed with water and evaporated to dryness. The residue was purified by column chromatography on silica gel using a chloroform/methanol 95: 5 mixture. The fractions containing Pc1-p were combined and evaporated (95 mg, 78\%). UV-Vis $\left(\mathrm{CHCl}_{3}\right) \lambda_{\max } \mathrm{nm} \mathrm{336,} \mathrm{618,}$ 684. ${ }^{1} \mathrm{H}$ NMR (300 MHz, $\mathrm{CD}_{2} \mathrm{Cl}_{2}$ ): $\delta$, ppm: 9.04-6.74 (m, 24H), 5.51-3.28 (m, 58H), 2.22-2.04 (m, 57H). FT-IR (ATR) $\nu / \mathrm{cm}^{-1}$ 1037, 1236, 1372, 1750, 2924. MALDI-MS $\mathrm{m} / \mathrm{z}$ : calcd for 
$\mathrm{C}_{132} \mathrm{H}_{142} \mathrm{~N}_{14} \mathrm{O}_{57} \mathrm{Zn}$ 2902.01: found: 2901.73. HRMS $\mathrm{m} / \mathrm{z}$ calcd for $\mathrm{C}_{132} \mathrm{H}_{142} \mathrm{~N}_{14} \mathrm{O}_{57} \mathrm{ZnNaH} 1462.3966$, found 1462.4022; calcd for $\mathrm{C}_{132} \mathrm{H}_{142} \mathrm{~N}_{14} \mathrm{O}_{57} \mathrm{ZnNa}_{3}$ 989.9215, found 989.9258.

Synthesis of Pc2-p. To a vigorously stirred solution of 1,8(11),15(18)-tri-(2-mercaptopyridine)-23(24)-3-(2-\{2-[2-(2-azodoethoxy)-ethoxy]ethoxy\}ethoxy) phthalocyaninato zinc(II) (9) (47 mg, $42 \mu \mathrm{mol})$ in $\mathrm{CH}_{2} \mathrm{Cl}_{2}(2 \mathrm{~mL}) \mathrm{CuSO}_{4} \cdot 5 \mathrm{H}_{2} \mathrm{O}(40 \mathrm{mg}, 160 \mu \mathrm{mol})$, (+)sodium L-ascorbate (40 mg, $200 \mu \mathrm{mol}), \beta$-D-glucopyranose, 2,3,4,6-tetra-O-acetyl- $\alpha$-D-glucopyranosyl-( $\rightarrow$ 4)-O-2,3,6-tri-Oacetyl- $\alpha$-D-glucopyranosyl-( $1 \rightarrow 4)$ - $O-2,3,6$-tri- $O$-acetyl- $\alpha$-D-glucopyranosyl-(1 $\rightarrow$ 4)-O-2,3,6-tri-O-acetyl- $\alpha$-D-glucopyranosyl-(1 $\rightarrow 4)$ $O-2,3,6$-tri- $O$-acetyl- $\alpha$-D-glucopyranosyl-(1 $\rightarrow$ 4)-2,3,6-triacetate 1-(prop-2'-ynyloxy) (115 mg, $63 \mu \mathrm{mol})$ were added consecutively. After $18 \mathrm{~h}$ of stirring in the dark at rt, $\mathrm{CH}_{2} \mathrm{Cl}_{2}$ and $\mathrm{H}_{2} \mathrm{O}$ were added. The organic phase was separated, washed with water and evaporated to dryness. The residue was purified by column chromatography on silica gel using a chloroform/methanol 95: 5 mixture. The fractions containing Pc1-p were combined and evaporated (107 mg, 86\%). UV-Vis $\left(\mathrm{CHCl}_{3}\right) \lambda_{\max } \mathrm{nm} \mathrm{337,}$ 630, 700. ${ }^{1} \mathrm{H}$ NMR $\left(300 \mathrm{MHz}, \mathrm{CD}_{2} \mathrm{Cl}_{2}\right): \delta$, ppm: 9.19-6.97 (m, $24 \mathrm{H}), 5.33-2.47(\mathrm{~m}, 58 \mathrm{H}), 2.08-1.66$ (m, 57H). FT-IR (ATR) $\nu / \mathrm{cm}^{-1} 1024,1213,1369,1741,2985$. MALDI-MS $\mathrm{m} / \mathrm{z}$ : calcd for $\mathrm{C}_{132} \mathrm{H}_{142} \mathrm{~N}_{14} \mathrm{O}_{54} \mathrm{~S}_{3} \mathrm{Zn}$ 2950.19: found: 2949.73. HRMS $\mathrm{m} / \mathrm{z}$ calcd for $\mathrm{C}_{132} \mathrm{H}_{142} \mathrm{~N}_{14} \mathrm{O}_{54} \mathrm{~S}_{3} \mathrm{ZnH}$ 2949.7349, found 2949.7279; calcd for $\mathrm{C}_{132} \mathrm{H}_{142} \mathrm{~N}_{14} \mathrm{O}_{54} \mathrm{~S}_{3} \mathrm{ZnNa} 2970.7173$, found 2970.7105 .

Synthesis of Pc1-d. Deprotection of the sugar moiety: $50 \mathrm{mg}$ of Pc1-p was dissolved in a 1:1 mixture of dichloromethane/ methanol and a catalytic amount (4-5 drops) of $25 \% \mathrm{NaOMe}$ solution in methanol was added. The mixture was stirred at $\mathrm{rt}$ overnight. The formed precipitate was centrifuged, washed with dichloromethane and dried. Yield: $32 \mathrm{mg}, 88 \%$. UV-Vis $\left(\mathrm{H}_{2} \mathrm{O}\right) \lambda_{\max }$ $\mathrm{nm}$ 320, 644, 685. FT-IR (ATR) $\nu / \mathrm{cm}^{-1}$ 1021, 1408, 1508, 3418br. MALDI-MS m/z: calcd for $\mathrm{C}_{94} \mathrm{H}_{104} \mathrm{~N}_{14} \mathrm{O}_{38} \mathrm{Zn}$ 2103.31: found: 2103.61 .

Synthesis of Pc2-d. Deprotection of the sugar moiety: $50 \mathrm{mg}$ of Pc2-p was dissolved in a 1:1 mixture of dichloromethane/ methanol and a catalytic amount (4-5 drops) of $25 \% \mathrm{NaOMe}$ solution in methanol was added. The mixture was stirred at $\mathrm{rt}$ overnight. The formed precipitate was centrifuged, washed with dichloromethane and dried. Yield: $33 \mathrm{mg}$, 93\%. UV-Vis $\left(\mathrm{H}_{2} \mathrm{O}\right) \lambda_{\max } \mathrm{nm} 334,654,704$. FT-IR (ATR) $\nu / \mathrm{cm}^{-1} 1024,1333$, 1408, 1574, 3281. MALDI-MS m/z: calcd for $\mathrm{C}_{94} \mathrm{H}_{104} \mathrm{~N}_{14} \mathrm{O}_{35} \mathrm{~S}_{3} \mathrm{Zn}$ 2151.49: found: 2151.39 .

\section{Photophysical characterization}

Absorption spectra were recorded on a Varian Cary 5000 double-beam UV-Vis-NIR spectrometer and baseline corrected. Steady-state emission spectra were recorded on a FluoTime300 spectrometer from PicoQuant equipped with a $300 \mathrm{~W}$ ozonefree Xe lamp (250-900 nm), a $10 \mathrm{~W}$ Xe flash-lamp (250-900 nm, pulse width $<10 \mu \mathrm{s}$ ) with repetition rates of $0.1-300 \mathrm{~Hz}$, an excitation monochromator (Czerny-Turner $2.7 \mathrm{~nm} \mathrm{~mm}^{-1}$ dispersion, 1200 grooves per $\mathrm{mm}$, blazed at $300 \mathrm{~nm}$ ), diode lasers (pulse width $<80 \mathrm{ps}$ ) operated by a computer-controlled laser driver PDL-820 (repetition rate up to $80 \mathrm{MHz}$, burst mode for slow and weak decays), two emission monochromators (Czerny-Turner, selectable gratings blazed at $500 \mathrm{~nm}$ with
$2.7 \mathrm{~nm} \mathrm{~mm}{ }^{-1}$ dispersion and 1200 grooves per $\mathrm{mm}$, or blazed at $1250 \mathrm{~nm}$ with $5.4 \mathrm{~nm} \mathrm{~mm}{ }^{-1}$ dispersion and 600 grooves per $\mathrm{mm}$ ), Glan-Thompson polarizers for excitation (Xe-lamps) and emission, a Peltier-thermostatized sample holder from Quantum Northwest $\left(-40{ }^{\circ} \mathrm{C}\right.$ to $\left.105{ }^{\circ} \mathrm{C}\right)$, and two detectors, namely a PMA Hybrid 40 (transit time spread FWHM $<120$ ps, 300-720 nm) and a R5509-42 NIR-photomultiplier tube (transit time spread FWHM 1.5 ns, 300-1400 nm) with external cooling $\left(-80^{\circ} \mathrm{C}\right)$ from Hamamatsu. Steady-state and fluorescence lifetimes were recorded in the TCSPC mode using a PicoHarp 300 (minimum base resolution 4 ps). Emission and excitation spectra were corrected for source intensity (lamp and grating) by standard correction curves. Phosphorescence lifetimes were recorded using a NanoHarp 250 (minimum base resolution $32 \mathrm{~ns}$ ) in the MCS mode. Lifetime analysis was performed using the commercial FluoFit software. The quality of the fit was assessed by minimizing the reduced chi squared function $\left(\chi^{2}\right)$ and visual inspection of the weighted residuals and their autocorrelation. Luminescence quantum yields were measured using a Hamamatsu Photonics absolute PL quantum yield measurement system (C9920-02) equipped with a L9799-01 CW Xenon light source (150 W), a monochromator, a C7473 photonic multi-channel analyzer, and an integrating sphere and by employing U6039-05 PLQY measurement software (Hamamatsu Photonics, Ltd, Shizuoka, Japan). All solvents used were of spectrometric grade.

\section{Determination of singlet molecular oxygen quantum yields}

The relative singlet oxygen quantum yields $\Phi_{\Delta}$ were determined by comparison with tetra-t-butylphthalocyaninato zinc(II) in $\mathrm{CHCl}_{3}\left(\Phi_{\Delta}=0.58\right)$ and DMF $\left(\Phi_{\Delta}=0.56\right)$ as a reference. ${ }^{32}$ The near infra-red phosphorescence spectrum of the photogenerated singlet oxygen was acquired and employed for the quantification of $\Phi_{\Delta}$. For this purpose, the area under the ${ }^{1} \mathrm{O}_{2}$ phosphorescence spectrum is plotted as a function of the fraction of absorbed light $\left(1-10^{-A}\right)$ at three different concentrations of the reference and of the sample. The slopes of these plots $\left(r_{\mathrm{R}}\right.$ and $r_{\mathrm{S}}$ respectively) are proportional to the corresponding $\Phi_{\Delta}^{\mathrm{R}}$ and $\Phi_{\Delta}^{\mathrm{S}}$ (where R stands for reference and S stands for sample). Thus, the $\Phi_{\Delta}^{\mathrm{S}}$ can be estimated according to the following equation:

$$
\Phi_{\Delta}^{\mathrm{S}}=\Phi_{\Delta}^{\mathrm{R}} r_{\mathrm{S}} / r_{\mathrm{R}}
$$

\section{Binding to human serum albumin}

The emission spectra of HSA were recorded in the wavelength range of 290-450 $\mathrm{nm}$ upon excitation at $280 \mathrm{~nm}$. HSA samples $(2.0 \mu \mathrm{M})$ were titrated with the derivatives Pc1-d and Pc2-d by using an Eppendorf pipette with the final concentration of PSs in the range of $0-10 \mu \mathrm{M}$. When molecules are bound independently to a set of equivalent sites on a macromolecule, the binding constant $\left(K_{\mathrm{a}}\right)$ and the numbers of binding sites $(n)$ can be determined by the following equation:

$$
\log \left[\left(F_{0}-F\right) / F\right]=\log K_{\mathrm{a}}+n \log [\mathrm{Pc}]
$$

where $F_{0}$ and $F$ are the fluorescence intensities in the absence and presence of corresponding phthalocyanine. This equation was applied to fit the spectral data, yielding a linear plot. 


\section{Determination of partition coefficients}

1-Octanol/water partition coefficients $\left(\log P_{\mathrm{o} / \mathrm{w}}\right)$ were determined at $25{ }^{\circ} \mathrm{C}$ using equal volumes of water $(2 \mathrm{~mL})$ and 1-octanol $(2 \mathrm{~mL})$. The final concentration of the compound was approx. $50 \mu \mathrm{M}$. The mixture was stirred for $1 \mathrm{~h}$ and centrifuged $(10 \mathrm{~min}$, $4400 \mathrm{rpm})$ to enable a phase separation. An aliquot $(50 \mu \mathrm{L})$ of aqueous and organic phases was dissolved in $1 \mathrm{~mL}$ of DMF and the final concentration was determined by absorption spectroscopy. $\log P_{\mathrm{o} / \mathrm{w}}$ was calculated according to the following equation:

$$
\log P_{\mathrm{o} / \mathrm{w}}=\log ([\mathrm{PS}] \text { octanol} /[\mathrm{PS}] \text { water })
$$

\section{Procedure for theoretical calculations}

Geometries were optimized by means of the density functional theory (DFT) method. ${ }^{33}$ B3LYP $^{34}$ was used in the Gaussian 09 program. ${ }^{35}$ For all calculations, we used the $6-311 \mathrm{G}(\mathrm{d}, \mathrm{p})$ basis set for all atoms. No imaginary frequency was obtained $($ NImag $=0)$. Simulated electronic spectra were computed on the optimized geometry at $\mathrm{S}_{0}$ by means of time-dependent density functional theory (TD-DFT) calculations. All the calculations were performed for vacuum conditions. The molecular orbitals were visualized using the GaussView 5.0 program.

\section{Cell culture conditions and cytotoxicity assay}

COLO 818 cells (DSMZ, Germany, ACC-81) were cultivated in RPMI 1640 (Biochrom, Germany) containing 10\% fetal bovine serum (Biochrom, Germany) at $37{ }^{\circ} \mathrm{C}$ and $5 \% \mathrm{CO}_{2}$ in a humidified atmosphere. Samples of Pc1-d and Pc2-d were dissolved in water to a concentration of $1 \mathrm{mg} \mathrm{mL} \mathrm{m}^{-1}$ and diluted to the final concentration. Stock solutions were stored at $-20{ }^{\circ} \mathrm{C}$ until required. For the cytotoxicity assays $3.6 \times 10^{3}$ cells were seeded in cell culture media containing $20 \mathrm{mM}$ HEPES and incubated for $12 \mathrm{~h}$ with Pc1-d and Pc2-d at different concentrations (each $10 \mu \mathrm{g} \mathrm{mL} L^{-1}, 5 \mu \mathrm{g} \mathrm{mL}{ }^{-1}, 1 \mu \mathrm{g} \mathrm{mL}{ }^{-1}$ ), subsequently followed by irradiation at $610 \mathrm{~nm}$ with $10 \mathrm{~mW} \mathrm{~cm}{ }^{-2}$ for one hour. For the controls, cells were kept in the dark under the same conditions. Luminescence was measured using a FluoStar Optima microplate reader (BMG Labtech, Germany). The cell viability in each well was calculated from the obtained values as a percentage of control wells using the CellTiter-Flour ${ }^{\mathrm{TM}}$ Cell Viability Assay (Promega $\mathrm{GmbH}$ ). The results were presented as a mean and standard deviation obtained from 3 independent experiments.

\section{Acknowledgements}

Generous financial support from the DFG EXC 1003 Cells in Motion-Cluster of Excellence, projects PP-2014-08 and FF-2013-10, is gratefully appreciated. Judith Schmidt is acknowledged for excellent technical assistance.

\section{Notes and references}

1 D. E. J. G. J. Dolmans, D. Fukumura and R. K. Jain, Nat. Rev. Cancer, 2003, 3, 380-387.

2 M. R. Hamblin and T. Hasan, Photochem. Photobiol. Sci., 2004, 3, 436-450.
3 R. R. Allison and C. H. Sibata, Photodiagn. Photodyn. Ther., 2010, 7, 61-75.

4 (a) M. R. Detty, S. L. Gibson and S. J. Wagner, J. Med. Chem., 2004, 47, 3897-3915; (b) R. R. Allison, G. H. Downie, R. Cuenca, X.-H. Hu, C. J. Childs and C. H. Sibata, Photodiagn. Photodyn. Ther., 2004, 1, 27-42.

5 (a) N. Mehraban and H. S. Freeman, Materials, 2015, 8, 4421-4456; (b) L. M. O. Loureno, P. M. R. Pereira, E. Maciel, M. Válega, F. M. J. Domingues, M. R. M. Domingues, M. G. P. M. S. Neves, J. A. S. Cavaleiro, R. Fernandes and J. P. C. Tomé, Chem. Commun., 2014, 50, 8363-8366; (c) B. Zhao, W. Duan, P. C. Lo, L. Duan, C. Wu and D. K. P. Ng, Chem. - Asian J., 2013, 8, 55-59.

6 (a) D. Topkaya, D. Lafont, F. Poyer, G. Garcia, F. Albrieux, P. Maillard, Y. Bretonnière and F. Dumoulin, New J. Chem., 2016, 40, 2044-2050; (b) Y. Mikata, M. Shibata, Y. Baba, T. Kakuchi, M. Nakai and S. Yano, J. Porphyrins Phthalocyanines, 2012, 16, 1177-1185; (c) B. Di Stasio, C. Frochot, D. Dumas, P. Even, J. Zwier, A. Müller, J. Didelon, F. Guillemin, M. L. Viriot and M. Barberi-Heyob, Eur. J. Med. Chem., 2005, 40, 1111-1122; (d) A. Galstyan, U. Kauscher, D. Block, B. J. Ravoo and C. A. Strassert, ACS Appl. Mater. Interfaces, 2016, 8, 12631-12637.

7 (a) V. K. Tiwari, R. C. Mishra, A. Sharma and R. P. Tripathi, Mini-Rev. Med. Chem., 2012, 12, 1497-1519; (b) A. Galstyan, D. Block, S. Niemann, M. Grüner, S. Abbruzzetti, M. Oneto, C. G. Daniliuc, S. Hermann, C. Viappiani, M. Schäfers, B. Löffler, C. A. Strassert and A. Faust, Chem. - Eur. J., 2016, 22(15), 5243-5252.

8 (a) S. Singh, A. Aggarwal, N. V. S. D. K. Bhupathiraju, G. Arianna, K. Tiwari and C. M. Drain, Chem. Rev., 2015, 115, 10261-10306; (b) L. M. O. Loureno, M. G. P. M. S. Neves, J. A. S. Cavaleiro and J. P. C. Tomé, Tetrahedron, 2014, 70, 2681-2698.

9 (a) A. O. Ribeiro, J. P. C. Tomé, M. G. P. M. S. Neves, A. C. Tomé, J. A. S. Cavaleiro, Y. Iamamoto and T. Torres, Tetrahedron Lett., 2006, 47, 9177-9180; (b) P. Zhang, S. Zhang and G. Han, Molecules, 2009, 14, 3688-3693; (c) J.-Y. Liu, P.-C. Lo, W.-P. Fong and D. K. P. Ng, Org. Biomol. Chem., 2009, 7, 1583-1591.

10 (a) A. O. Ribeiro, J. P. C. Tome, M. G. P. M. S. Neves, A. C. Tome, J. A. S. Cavaleiro, O. A. Serra and T. Torres, Tetrahedron, 2006, 47, 6129-6132; (b) M. A. Ermeydan, F. Dumoulin, T. V. Basova, D. Bouchu, A. G. Gurek, V. Ahsen and D. Lafont, New J. Chem., 2010, 34, 1153-1162.

11 Y. N. Konan, R. Gurny and E. Allemann, J. Photochem. Photobiol., B, 2002, 66, 89-106.

12 R. K. Pandey and G. Zheng, in The Porphyrin Handbook, ed. K. M. Kadish, K. M. Smith and R. Guilard, Academic Press, Boston, 2000, vol. 6, pp. 157-230.

13 L. B. Josefsen and R. W. Boyle, Theranostics, 2012, 2, 916-966. 14 (a) T. Furuyama, K. Satoh, T. Kushiya and N. Kobayashi, J. Am. Chem. Soc., 2014, 136, 765-776; (b) T. T. Tasso, Y. Yamasaki, T. Furuyama and N. Kobayashi, Dalton Trans., 2014, 43, 5886-5892.

15 G. Schmid, M. Sommerauer, M. Geyer and M. Hanack, in Phthalocyanines, Properties and Applications, ed. C. C. Leznoff and A. B. P. Lever, VCH, New York, 1996, vol. 4. 
16 T. P. Mthethwa, S. Tuncel, M. Durmu and T. Nyokong, Dalton Trans., 2013, 42, 4922-4930.

17 (a) Phthalocyanines: properties and applications, ed. C. C. Leznoff and A. B. P. Lever, VCH, New York, NY, 1989, vol. 1-4; (b) M. Kasha, H. R. Rawls and M. A. El-Bayoumi, Pure Appl. Chem., 1965, 11, 371-392.

18 (a) Photosensitizers in Medicine, Environment, and Security, ed. T. Nyokong and V. Ahsen, Springer, 2012; (b) I. O. L. Bacellar, T. M. Tsubone, C. Pavani and M. S. Baptista, Int. J. Mol. Sci., 2015, 16, 20523-20559; (c) N. Cauchon, H. Tian, R. Langlois, C. L. Madeleine, S. Martin, H. Ali, D. Hunting and J. E. van Lier, Bioconjugate Chem., 2005, 16(1), 80-89; (d) B. M. Aveline, T. Hasan and R. W. Redmond, J. Photochem. Photobiol., B, 1995, 30(2-3), 161-169.

19 (a) L. Vachova, M. Machacek, R. Kučera, J. Demuth, P. Cermak, K. Kopecky, M. Miletin, A. Jedlickova, T. Simunek, V. Novakova and P. Zimcik, Org. Biomol. Chem., 2015, 13, 5608-5612; (b) S. Z. Topal, Ü. Isci, U. Kumru, D. Atilla, A. G. Gürek, C. Hirel, M. Durmus, J.-B. Tommasino, D. Luneau, S. Berber, F. Dumoulin and V. Ahsen, Dalton Trans., 2014, 43, 6897-6908.

20 M. M. Ayhan, G. Altınbaş Özpinar, M. Durmuş and A. G. Gürek, Dalton Trans., 2013, 42, 14892-14904.

21 A. P. Casteno, T. N. Demidova and M. R. Hamblin, Photodiagn. Photodyn. Ther., 2004, 1(4), 279-293.

22 (a) S. E. Smith, J. M. Williams, S. Ando and K. Koide, Anal. Chem., 2014, 86, 2332-2336; (b) A. Yuan, J. Wu, C. Song, X. Tang, Q. Qiao, L. Zhao, G. Gong and Y. Hu, J. Pharm. Sci., 2013, 102, 1626-1635.

23 (a) Z. Sheng, D. Hu, M. Zheng, P. Zhao, H. Liu, D. Gao, P. Gong, G. Gao, P. Zhang, Y. Ma and L. Cai, ACS Nano, 2014, 8, 12310-12322; (b) Q. Chen, C. Liang, X. Wang, J. He, Y. Li and Z. Liu, Biomaterials, 2014, 35, 9355-9362; (c) H. Maeda, Bioconjugate Chem., 2010, 21, 797-802.

24 V. S. Jisha, K. T. Arun, M. Hariharan and D. Ramaiah, J. Am. Chem. Soc., 2006, 128, 6024-6025.

25 (a) S. Baek and K. Na, Colloids Surf., B, 2013, 101, 493-500; (b) Y. D. Lee, H. J. Cho, M. H. Choi, H. Park, J. Bang, S. Lee, I. C. Kwon and S. Kim, J. Controlled Release, 2015, 209, 12-19.
26 Advances in Photodynamic Therapy: Basic, Translational, and Clinical, ed. M. Hamblin and P. Mroz, Artech House, 2008.

27 Drug Delivery and Targeting, ed. A. M. Hillery, A. W. Lloyd and J. Swarbrick, Taylor and Francis, 2001.

28 O. J. Norum, P. K. Selbo, A. Weyergang, K. E. Giercksky and K. Berg, J. Photochem. Photobiol., B, 2009, 96, 83-92.

29 I. Baldea and A. G. Filip, J. Physiol. Pharmacol., 2012, 63(2), 109-118.

30 S. Tuncel, F. Dumoulin, J. Gailer, M. Sooriyaarachchi, D. Atilla, M. Durmuş, D. Bouchu, H. Savoie, R. W. Boyle and V. Ahsen, Dalton Trans., 2011, 40, 4067-4079.

31 N. Sehlotho, M. Durmuş, V. Ahsen and T. Nyokong, Inorg. Chem. Commun., 2008, 11, 479-483.

32 W. Spiller, H. Kliesch, D. Wöhrle, S. Hackbarth, B. Röder and G. Schnurpfeil, J. Porphyrins Phthalocyanines, 1998, 2(2), 145-158.

33 M. E. Casida, Recent Adv. Comput. Chem., 1995, 1, 155-181. 34 (a) A. D. Becke, J. Chem. Phys., 1993, 98, 5648-5652; (b) C. Lee, W. Yang and R. G. Parr, Phys. Rev. B: Condens. Matter Mater. Phys., 1988, 37, 785-789.

35 M. J. Frisch, G. W. Trucks, H. B. Schlegel, G. E. Scuseria, M. A. Robb, J. R. Cheeseman, G. Scalmani, V. Barone, B. Mennucci, G. A. Petersson, H. Nakatsuji, M. Caricato, X. Li, H. P. Hratchian, A. F. Izmaylov, J. Bloino, G. Sonnenberg, J. L. Zheng, M. Hada, M. Ehara, K. Toyota, R. Fukuda, J. Hasegawa, M. Ishida, T. Nakajima, Y. Honda, O. Kitao, H. Nakai, T. Vreven, J. A. Montgomery Jr., J. E. Peralta, F. Ogliaro, M. Bearpark, J. J. Heyd, E. Brothers, K. N. Kudin, V. N. Staroverov, R. Kobayashi, J. Normand, K. Raghavachari, A. Rendell, J. C. Burant, S. S. Iyengar, J. Tomasi, M. Cossi, N. Rega, N. J. Millam, M. Klene, J. E. Knox, J. B. Cross, V. Bakken, C. Adamo, J. Jaramillo, R. Gomperts, R. E. Stratmann, O. Yazyev, A. J. Austin, R. Cammi, C. Pomelli, J. W. Ochterski, R. L. Martin, K. Morokuma, V. G. Zakrzewski, G. A. Voth, P. Salvador, J. J. Dannenberg, S. Dapprich, A. D. Daniels, Ö. Farkas, J. B. Foresman, J. V. Ortiz, J. Cioslowski and D. J. Fox, Gaussian 09, Gaussian, Inc., Wallingford, CT, 2009. 